\title{
Crassulaceae endémicas del Perú
}

\section{Blanca León ${ }^{1,2}$}

${ }^{1}$ Museo de Historia Natural, Av. Arenales 1256, Aptdo. 14-0434, Lima 14, Perú

2 Plant Resources Center, University of Texas at Austin, Austin TX 78712 EE.UU.

blanca.leon@mail.utexas.edu

\section{Resumen}

La familia Crassulaceae es reconocida en el Perú por presentar cinco géneros y 29 especies (Brako \& Zarucchi, 1993), mayormente arbustos y hierbas. En este trabajo reconocemos 13 especies y dos variedades como endemismos peruanos en tres géneros. Echeveria es el género con el mayor número de especies endémicas. Los taxones endémicos ocupan principalmente las regiones Mesoandina y Puna Húmeda y Seca, entre los 1700 y $4500 \mathrm{~m}$ de altitud. Se aplicaron las categorías y criterios de la UICN a nueve taxones. Dos Crassulaceae endémicas están representados dentro del Sistema Nacional de Áreas Naturales Protegidas por el Estado.

Palabras claves: Crassulaceae, Echeveria, Perú, endemismo, plantas endémicas.

\section{Abstract}

The Crassulaceae are represented in Peru by five genera and 29 species (Brako \& Zarucchi, 1993), mostly shrubs and herbs. Here we recognize as endemics 13 species and two varieties in three genera. Echeveria is the genus with the largest number of endemic species. Endemic taxa grow in Mesoandean, and Humid and Dry Puna regions, between 1700 and 4500 m elevation. We applied IUCN categories and criteria to nine taxa. Two endemic Crassulaceae have been found in Peru's protected areas system.

Keywords: Crassulaceae, Echeveria, Peru, endemism, endemic plants.

\section{Echeveria chiclensis (Ball) Berger var. backebergii (Poelln.) Pino}

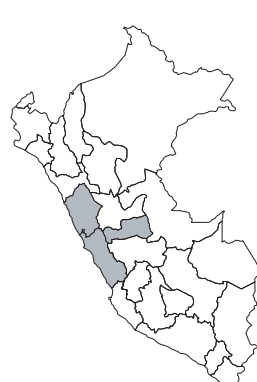

\section{EN, B1ab(iii)}

Publicación: Haseltonia 9: 55. 2002. Colección tipo: C. Backeberg 2 Herbarios: B.

Nombre común: Desconocido.

Registro departamental: AN, LI, PA. Regiones Ecológicas: MA; 2030—3800 $\mathrm{m}$

SINANPE: Sin registro.

Herbarios peruanos: USM (4).

Observaciones: Esta hierba suculenta es conocida de varias localidades a lo largo de las cuencas medias y alta del Pativilca y Rímac. Una población se halla muy cerca de una zona de interés para la conservación, el Bosque de Zárate. Amenazas potenciales a esta variedad provienen de los incendios intencionales y el pastoreo intensivo, aunque su presencia entre intersticios rocosos podría conferirle ciertas ventajas. Probablemente. su rango de distribución incluya otras cuencas de la vertiente occidental entre las localidades conocidas, por lo que falta mayores observaciones de campo para especies que como esta habitan la región mesoandina.

\section{Echeveria chiclensis (Ball) Berger var. chiclensis}

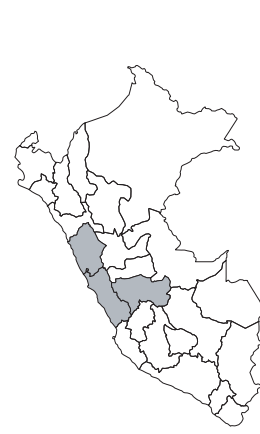

\section{NT}

Publicación:

Colección tipo: J. Ball s.n.

Herbarios: $\mathrm{K}$.

Nombre común: Desconocido.

Registro departamental: AN, JU, LI.

Regiones Ecológicas: MA, PSH; 1735$4240 \mathrm{~m}$.

SINANPE: Sin registro.

Herbarios peruanos: USM (13).
Observaciones: Hierba suculenta, conocida del centro del país tanto de la vertiente occidental como de valles interandinos. Está bien representada en los herbarios peruanos tanto en número como a través de los años; falta, sin embargo, conocer detalles de su biología y el tamaño de sus poblaciones. No se sabe si los incendios intencionales y el pastoreo caprino afectan a este taxón.

\section{Echeveria decumbens Kimnach}

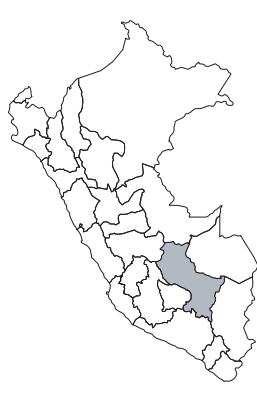

$$
\text { CR, B1a }
$$

Publicación: Cact. Succ. J. (Los Angeles) 67(1): 4-5, f. 1-3. 1995.

Colección tipo: W. Baker 4143a

Herbarios: HNT, US.

Nombre común: Desconocido.

Registro departamental: CU.

Regiones Ecológicas: MA; $3150 \mathrm{~m}$.

SINANPE: Sin registro.

Herbarios peruanos: Ninguno.

Observaciones: Esta hierba se conoce solamente de la localidad tipo, en la cuenca del Yanatili, afluente del Urubamba, una zona poco herborizada. Aparentemente, no ha vuelto a ser recolectada desde inicios de la década de 1980. Al igual que otras numerosas especies que conforman la vegetación de ambientes abiertos o semixéricos, su representación en colecciones botánicas es deficiente.

\section{Echeveria eurychlamys (Diels) Berger}

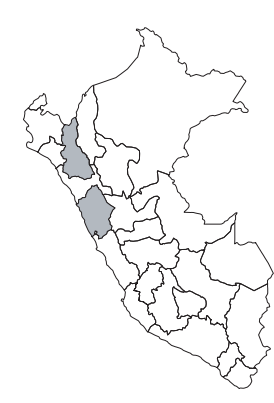

\section{EN, B1a}

Publicación: Nat. Pflanzenfam. (ed. 2) 18a: 473. 1930.

Colección tipo: A. Weberbauer 4056

Herbarios: B.

Nombre común: Desconocido.

Registro departamental: AN, CA.

Regiones Ecológicas: MA, BS; 2350$3100 \mathrm{~m}$.

SINANPE: Sin registro.

Herbarios peruanos: CPUN (1), USM (1). 
Observaciones: Hierba conocida de poblaciones dispersas en las cuencas del Chotano, Llaucano y del Marañón. Los ejemplares de herbarios que se conocen representan mayormente poblaciones recolectadas una sola vez, desconociéndose el estatus actual de estas.

\section{Echeveria excelsa (Diels) Berger}

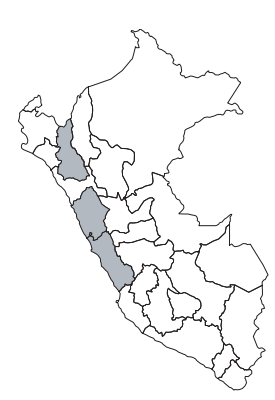

\section{VU, B1ab(iii)}

Publicación: Nat. Pflanzenfam. (ed. 2) 18a: 473. 1930

Colección tipo: A. Weberbauer 3149

Herbarios: B.

Nombre común: Desconocido.

Registro departamental: AN, CA, LI

Regiones Ecológicas: AA, MA, PSH; 1980-4500 m.

SINANPE: PNH

Herbarios peruanos: USM (2).

Observaciones: Hierba suculenta, conocida de la vertiente occidental y valles interandinos en el norte y centro del país. Ha sido recolectada en las cuencas del Marañón, Santa y Rímac. Tanto su rango geográfico como altitudinal permite suponer que sus poblaciones sean más numerosas que las representadas en los herbarios. Con la excepción de las poblaciones en el Parque Nacional Huascarán, las otras localidades solamente han sido herborizadas una sola vez, por lo que se desconoce las condiciones precisas de las poblaciones; sin embargo, es posible considerar que los incendios intencionales podrían afectar a esta especie.

\section{Echeveria oreophila Kimnach}

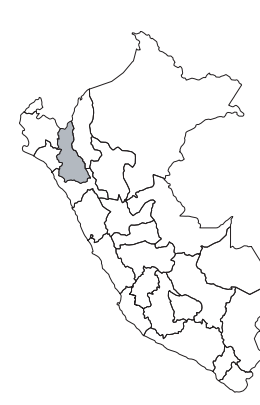

\section{EN, B1ab(iii)}

Publicación: Cact. Succ. J. (Los Angeles) 74(6): 290—292, f. 10. 2002.

Colección tipo: R. Bauer \& M. Kimnach 10

Herbarios: SM; $\underline{\text { HUT }}$

Nombre común: Desconocido.

Registro departamental: CA.

Regiones Ecológicas: PAR; 3000—3500 m.

SINANPE: Sin registro.

Herbarios peruanos: HUT (isotipo citado).

Observaciones: Hierba suculenta descrita recientemente, que se conoce solamente de la colección tipo, en la cuenca del río Cajamarca. La localidad original está impactada por la actividades agrícolas y podría estar afectada por actividades mineras.

\section{Echeveria utcubambensis Hutchison ex Kimnach}

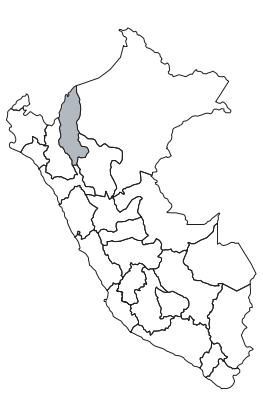

\section{EN, B1a}

Publicación: Cact. Succ. J. (Los Angeles) 74(6): 287-290, f. 5-6. 2002.

Colección tipo: P.C. Hutchison \& D.E. Bennett 4531

Herbarios: F, NY, UC.

Nombre común: Desconocido,

Registro departamental: AM.

Regiones Ecológicas: BS; 1475-1775 m.

SINANPE: Sin registro.

Herbarios peruanos: Ninguno.

Observaciones: Hierba suculenta, recientemente descrita, sobre la base de plantas recolectadas en la cuenca del Utcubamba. Poco se sabe del tamaño de las poblaciones. No pudo ubicarse las colecciones de herbario citadas para el Perú.

\section{Echeveria wurdackii Hutchison ex Kimnach}

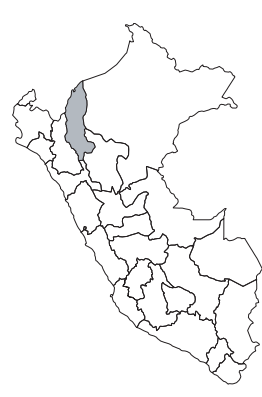

EN, B1a

Publicación: Cact. Succ. J. (Los Angeles) 74(6): 285-286, f. 2-3. 2002.

Colección tipo: J.J. Wurdack 1163

Herbarios: F, UC; USM!.

Nombre común: Desconocido.

Registro departamental: AM.

Regiones Ecológicas: BMHM; 2750$2850 \mathrm{~m}$.

SINANPE: Sin registro.

Herbarios peruanos: USM (isotipo).

Observaciones: Hierba suculenta, descrita recientemente y conocida sólo de la cuenca del Marañón. Localmente se la considera frecuente, pero no hay una evaluación detallada de las poblaciones. La localidad tipo es una zona de alto endemismo que debería recibir atención para su conservación.

\section{Sedum reniforme (H. Jacobsen) Thiede \& ' $t$ Hart VU, B1ab(iii)}

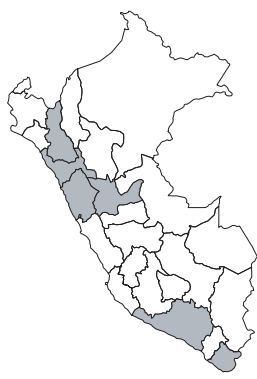

Publicación: Novon 9(1): 124. 1999.

Colección tipo: A. Weberbauer 4053

Herbarios: B; MOL!

Nombre común: Desconocido. Registro departamental: AN, AR, CA, HU, LL, TA.

Regiones Ecológicas: MA, PSH; 2600$4400 \mathrm{~m}$.

SINANPE: PNH

Herbarios peruanos: CPUN (1), HUT (2), MOL (isotipo).

Observaciones: Hierba conocida de varias poblaciones aisladas en valles interandinos y de las vertientes occidentales de Cajamarca a Tacna. Localmente las poblaciones cuentan con numerosos individuos, considerándose su presencia como frecuente. Al igual que otras especies de ambientes con estacionalidad de lluvias marcada, cambios climáticos deberían considerarse para su monitoreo. Amenazas a sus poblaciones podrían estar asociadas a construcción de caminos, minería e incendios intencionales.

\section{Sedum weberbaueri (Diels) Thiede \& 't Hart}

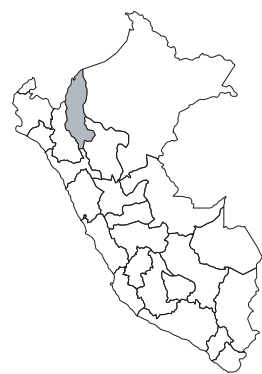

Publicación: Novon 9(1): 125. 1999.

Colección tipo: A. Weberbauer 4282

Herbarios: B; MOL!

Nombre común: Desconocido.

Registro departamental: AM.

Regiones Ecológicas: BS; $2300 \mathrm{~m}$.

SINANPE: Sin registro.

Herbarios peruanos: MOL (isotipo).

Observaciones: Hierba suculenta. Este taxón fue descrito posterior a Brako \& Zarucchi (1993); no ha sido posible evaluarlo, ni asignarle una categoría. 
11. Villadia andina (Ball.) Baehni \& J.F. Macbr.

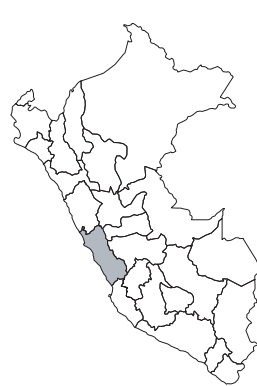

, B1ab(iii)

Publicación: Candollea 7: 285. 1937.

Colección tipo: J. Ball s.n.

Herbarios:

Nombre común: Desconocido.

Registro departamental: LI.

Regiones Ecológicas: MA, PSH; $3530 \mathrm{~m}$.

SINANPE: Sin registro.

Herbarios peruanos: USM?

Observaciones: Este taxón fue considerado por Brako \& Zarucchi (1993) como un endemismo; sin embargo, no ha sido posible evaluarlo, ni asignarle una categoría.

\section{Villadia berilloana (Hamet) Baehni \& J.F. Macbr.}

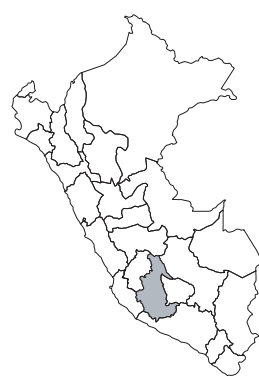

Publicación: Candollea 7: 285. 1937. Colección tipo: A. Weberbauer 5501 Herbarios: B, F.

Nombre común: Desconocido.

Registro departamental: AY.

Regiones Ecológicas: MA; $3000 \mathrm{~m}$.

SINANPE: Sin registro.

Herbarios peruanos: Ninguno.

Observaciones: Este taxón fue considerado por Brako \& Zarucchi (1993) como un endemismo; sin embargo, no ha sido posible evaluarlo, ni asignarle una categoría.

\section{Villadia dyvrandae (Hamet) Baehni \& J.F. Macbr.}

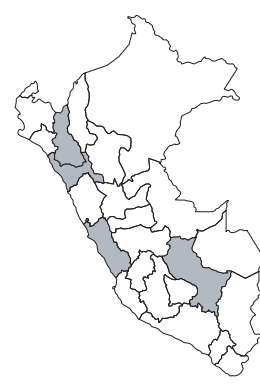

Publicación: Candollea 7: 286. 1937.

Colección tipo: A. Weberbauer 5278

Herbarios: B, F.

Nombre común: Desconocido.

Registro departamental: CA, CU, LL, LI.

Regiones Ecológicas: MA; 2400—3300

$\mathrm{m}$.

SINANPE: Sin registro.

Herbarios peruanos: HUT (2).

Observaciones: Este taxón fue considerado por Brako \& Zarucchi (1993) como un endemismo; sin embargo, no ha sido posible evaluarlo, ni asignarle una categoría.

\section{Villadia grandyi (Hamet) Baehni \& J.F. Macbr.}

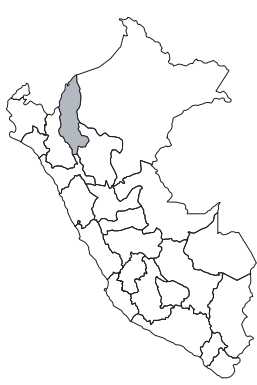

Publicación: Candollea 7: 286. 1937.

Colección tipo: W. Mathews s.n.

Herbarios: K.

Nombre común: Desconocido.

Registro departamental: AM.

Regiones Ecológicas: Sin datos; altitud desconocida.

SINANPE: Sin registro.

Herbarios peruanos: Ninguno.

Observaciones: Este taxón fue considerado por Brako \& Zarucchi (1993) como un endemismo; sin embargo, no ha sido posible evaluarlo, ni asignarle una categoría.

\section{Villadia incarum (Ball) Baehni \& J.F. Macbr.}

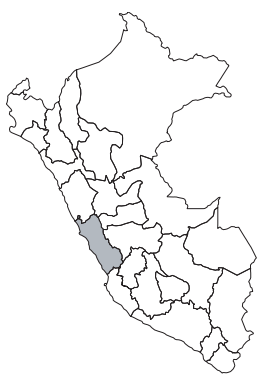

Publicación: Candollea 7: 286. 1937.

Colección tipo: J. Ball s.n.

Herbarios:

Nombre común: Desconocido.

Registro departamental: LI.

Regiones Ecológicas: PSH; 3900—4000

m.

SINANPE: Sin registro.

Herbarios peruanos: Ninguno.

Observaciones: Este taxón fue considerado por Brako \& Zarucchi (1993) como un endemismo; sin embargo, no ha sido posible evaluarlo, ni asignarle una categoría. 